Original Article

\title{
EVALUATION OF ANTIDIABETIC, HYPOLIPIDEMIC AND ANTIOXIDANT ACTIVITY OF POLYHERBAL FORMULATION IN STREPTOZOTOCIN-NICOTINAMIDE INDUCED DIABETES IN RATS
}

\author{
1YUVRAJ SINGH SURANA, PURNIMA ASHOK, 2RAJENDRAN R.
}

${ }^{1}$ Department of Pharmacology, KLE University College of Pharmacy, Bengaluru, KLE Academy of Higher Education and Research (KLE University), Belagavi, Karnataka, India, ${ }^{2}$ Green Chem Herbal Extracts and Formulation, Domlur, Bengluru.

Email: yuvrajsurana@gmail.com

Received: 15 Jun 2017 Revised and Accepted: 31 Aug 2017

\begin{abstract}
Objective: To evaluate antidiabetic, hypolipidemic and antioxidant activity of polyherbalformulation (PHF) aqueous extract in streptozotocinnicotinamide induced diabetes in rats.

Methods: Fasting blood glucose, lipid profiles, serum insulin and glycosylate haemoglobin (HbA1C) were determined in normal and streptozotocinnicotinamide induced diabetic rats after oral administration of the PHF for $45 \mathrm{~d}$. Antioxidant enzymes superoxide dismutase (SOD), catalase (CAT), glutathione (GSH) and malondialdehyde (MDA) levels were evaluated in kidney and liver tissue. Histopathological changes in diabetic rat vital organs were also observed after PHF treatment.

Results: Daily oral administration of PHF (200 and $400 \mathrm{mg} / \mathrm{kg}$, b.w.) and metformin ( $5 \mathrm{mg} / \mathrm{kg}$, b.w.) showed beneficial effects on blood glucose level $(\mathrm{P}<0.001)$ and hyperlipidaemia due to diabetes. The PHF treatment also enhances serum insulin level and body weight of diabetic rats as compared to diabetic control group. Furthermore, the PHF has favourable effects on histopathological studies, in streptozotocin-nicotinamide induced diabetes. Antioxidant enzymes and GSH levels were found to be significantly increased and levels of MDA were decreased in treated diabetic animals.
\end{abstract}

Conclusion: PHF possesses antidiabetic, hypolipidemic and antioxidant properties. PHF has also showed favourable effect on histopathological changes in streptozotocin-nicotinamide induced diabetic animals.

Keywords: Streptozotocin, Nicotinamide, Metformin, Polyherbal formulation

(C) 2017 The Authors. Published by Innovare Academic Sciences Pvt Ltd. This is an open access article under the CC BY license (http://creativecommons.org/licenses/by/4.0/) DOI: http://dx.doi.org/10.22159/ijpps.2017v9i10.20723

\section{INTRODUCTION}

Diabetes mellitus (DM) comprises a group of common metabolic disorders that share the phenotype of hyperglycaemia with disturbance in carbohydrate, lipid and protein metabolism resulting from impaired insulin secretion or insulin action [1]. DM is a major challenge in worldwide healthcare systems and strongly associated with several major health risk factors [2]. It can be seen as burden of diabetes increasing worldwide and estimation suggest that their number will be 366 million by 2030. Chronic hyperglycaemia is consider as a major risk factor in the development of secondary complications like cardiopathy, nephropathy, retinopathy and neuropathy [3]. Four prominent theories have been proposed to explain that how hyperglycaemia might lead to chronic complications of DM and these are; advanced glycosylation end products (AGEs), increase glucose metabolism via sorbitol pathway, increase the formation of diacylglycerol leading to activation of protein kinase (PKC) and elevated levels of blood glucose increase the flux through the hexosamine pathway, which produces fructose6-phosphate, a substrate for 0-linked glycosylation and proteoglycan production [4]. In diabetes there is a state of increased free radical production, which results from an imbalance between the radical generating and radical scavenging systems leading to an increased production of reactive oxygen species (ROS) including superoxide radical (02-), hydrogen peroxide (H2O2) and hydroxyl radical (OH-). It may include not only the increased non-enzymatic and auto-oxidation glycosylation but also involved in metabolic stress which results from change in energy metabolism, levels of inflammatory mediators and the status of antioxidant defences [5]. In spite of the availabilities of insulin and oral hypoglycaemic agents from natural and synthetic sources, diabetes and its secondary complications continue to be a major burden on world population [6]. Many Indian medicinal plants are reported to be useful in diabetes, which might provide new anti-diabetic drug and can counter the costlier and availability of present day drugs in the rural market [7]. India is a rich source of medicinal plants and in Ayurveda and Siddha system of medicines, number of plant extracts have been found to be useful to manage diabetes. The advantage of a traditional medicinal plant is fewer side effects with multiple therapeutic action due to the presence of different bioactive compounds. Following world health organisation (WHO) has recommended that the research on the beneficial uses of medicinal plants in the treatment of DM have also gained momentum [8]. Moreover diet and spice therapies become the major approaches recently for the management of diabetes; and a significant amount of work has been carried out with Momordica charantia Linn., Coccinia indica W. andA. and Lagerstroemia speciosa Linn. All of these herbs possess significant antidiabetic activity [9-11]; however their antioxidant activity in DM has not been thoroughly studied. In this view point, the present study has been taken up to determine the synergistic antidiabetic activity of the combination of these plants and compare its potential in streptozotocin-nicotinamide induced diabetic rats [12].

\section{MATERIALS AND METHODS}

\section{Chemicals}

Streptozotocin and nicotinamide (Sigma-Aldrich, USA), serum insulin kit (Mercodia, Swedan), HbA1C kit (Accurex Biomedical PVT. LTD. Maharashtra, India) and biochemical reagents for fasting blood sugar, lipid profile and for kidney function markers were purchased from Agapee diagnostics, India.

\section{Animals}

Healthy albino Wistar rats (200-250g) were procured from, a registered breeder. Animals were housed at institutes animal house facility in polypropylene cages and maintained under standard conditions $(12 \mathrm{~h}$ light/dark cycles, $22 \pm 2{ }^{\circ} \mathrm{C}$ and $55 \pm 5 \%$ relative humidity). They were fed 
with standard rat pellet diet and water ad libitum. The animals were kept in accordance with committee for the purpose of control and supervision of experimental animals (CPCSEA) guidelines for the care and use of laboratory animals. The study protocol was approved by institutional animal ethics committee (IAEC), KLE University's College of Pharmacy, Bengaluru (01/PA/2015).

\section{Preparation of solutions}

Test drug and metformin were dissolved in distilled water and administered orally for experimental purpose. All the drugs were freshly prepared each time before use.

\section{Determination of acute oral toxicity}

Acute oral toxicity of PHF was carried out according to organization for economic cooperation and development (OECD) guidelines 425 by using female albino Wistar rats (150-200g), which were maintained under standard conditions. Animals were kept under fasting $12 \mathrm{~h}$ prior to the experiment, water given ad libitum. Test drug was given to all animals in a single dose of $2000 \mathrm{mg} / \mathrm{kg}$ by using a stomach tube and all the animals were observed individually for signs of toxicity [13].

Animals observed for first four hours and thereafter for a total of $14 \mathrm{~d}$.

\section{Induction of diabetes and experimental design}

Diabetes was induced in overnight fasted animals (deprived of food $16 \mathrm{~h}$ but had been allow to free access to water) by a single intraperitoneal (i. p.) injection of streptozotocin (STZ) dissolved in citrate buffer ( $65 \mathrm{mg} / \mathrm{kg}$, b.w.) $15 \mathrm{~min}$ after the i. p. administration of $110 \mathrm{mg} / \mathrm{kg}$, b.w. of nicotinamide dissolved in normal saline. Hyperglycaemia was confirmed by elevated glucose levels in plasma, determined after $72 \mathrm{~h}$ injections of STZ. Animals with blood glucose concentration more than $200 \mathrm{mg} / \mathrm{dl}$ were used for the study. Diabetic animals were randomly divided into five groups containing twelve in each group. All groups receive STZ except normal control and the treatment protocol is as follows:

Group I-Normal control (saline treatment)

Group II-Positive control (STZ treatment)

Group III-Aqueous PHF (STZ+Dose I, 200 mg/kg, b.w.)

Group IV-Aqueous PHF (STZ+Dose II, 400 mg/kg, b.w.)

Group V-Standard group (STZ+Metformin, 5 mg/kg, b.w.)

The drugs were administered orally using an intragastric tube once daily for $45 \mathrm{~d}$, continuously. Body weight of animals was measured throughout the experiment. At the end of the experiment, the animals were fasted overnight and blood collected for various biochemical estimations. The animals were then sacrificed (under the influence of overdosed isoflurane anaesthesia). The kidney, liver and pancreas were quickly excised, immediately rinsed in ice-cold saline; a portion of the organs were fixed in $10 \%$ neutral buffered formalin for histopathological study and the remaining portion were stored for further biochemical estimations.

\section{Biochemical parameters}

Fasting blood glucose analysis was done using a commercially available kit (Agapee Diagnostic, India). Serum insulin levels were measured by the Elisa kit from Mercodia, Swedan. Glycosylated haemoglobin (HbA1C \%) was determined in EDTA-blood samples using a commercial assay kit (Accurex Biomedical PVT. LTD. Maharashtra, India). Blood samples were centrifuged at $7000 \mathrm{rpm}$ for $15 \mathrm{~min}$ at $4^{\circ} \mathrm{C}$ to separate the serum. Serum creatinine, uric acid and urea levels measured using the respective assay kits (Agapee Diagnostic, India) using a semi-automatic biochemical analyzer (RMS Biochemical Analyzer, Chandigarh, India).

\section{Lipid profiles}

The serum total cholesterol (TC), HDL-cholesterol (HDL-C) and triglyceride (TG) were measured using the respective assay kits (Agapee Diagnostic, India) using a semi-automatic biochemical analyzer. The fraction of very low-density lipoproteins (VLDL-C) and low-density lipoproteins (LDL-C) in the serum were calculated as follows-

\section{$\mathrm{VLDL}=\mathrm{TG} / 5$}

LDL=Total cholesterol-TG/5-HDL

\section{In vivo antioxidants}

A $10 \%(\mathrm{w} / \mathrm{v})$ homogenate of liver and kidney were prepared by using Remi homogenizer at a speed of $10,000 \mathrm{rpm}$. The homogenized tissue preparation was used to measure the levels of antioxidant enzymes in liver and kidney tissues. GSH was estimated according the method described by Pompella et al., CAT, SOD and lipid peroxidation (MDA content) were measured according to the method described by Sinha, Kakkar et al. and Ohkawa et al. [14-17].

\section{Histopathological studies}

At the end of the treatment, blood samples were collected (retro orbital plexus) from all the animals of different groups and then animals were sacrificed using mild anaesthesia (Isoflurane). The pancreas, kidney and liver tissues were collected and fixed in neutral formalin solution for $48 \mathrm{~h}$, dehydrated by passing through graded series of alcohol embedded in paraffin blocks and $4 \mu \mathrm{m}$ thick sections were prepared using a semi-automated rotator microtome.

\section{Statistical analysis}

All values are taken from mean \pm SEM. Graphpad prism version 5 was used for statistical analysis. Results of this study were compared by ANOVA, followed by Dunnett's Multiple Comparison Test.

\section{RESULTS}

\section{Acute oral toxicity test}

Acute oral toxicity study of PHF was done according to OECD guidelines for 425 and revealed the non-toxic nature of PHF at the limit test dose of $2000 \mathrm{mg} / \mathrm{kg}$ b.w. p. o till the end of the study.

\section{Effect of PHF and metformin on body weight in STZ induced animals}

The body weight of the diabetic rats showed a significant $(\mathrm{P}<0.001)$ decrease after the administration of STZ-nicotinamide. The treatment with PHF (Dose-I, $200 \mathrm{mg} / \mathrm{kg}$, Dose-II, $400 \mathrm{mg} / \mathrm{kg}$ ) and metformin shows mild reduction in b.w. compared with diabetic control rats [fig. 1].

Effect of PHF and metformin on blood glucose level, serum insulin level and glycosylated haemoglobin level in STZ induced animals

In the diabetic control rats, $\mathrm{HbA} 1 \mathrm{C}$ level was significantly $(\mathrm{P}<0.001)$ increased when compared to normal control rats. Diabetic rats treated with PHF (Dose-I, $200 \mathrm{mg} / \mathrm{kg}$, Dose-II, $400 \mathrm{mg} / \mathrm{kg}$ ) and metformin showed significant $(\mathrm{P}<0.001)$ reduction in $\mathrm{HbA1C}$ levels as compared to diabetic control rats. In the diabetic control rats, fasting blood glucose level was significantly $(\mathrm{P}<0.001)$ increased when compared to normal control rats. Diabetic rats treated with PHF (Dose-I, $200 \mathrm{mg} / \mathrm{kg}$, Dose-II, $400 \mathrm{mg} / \mathrm{kg}$ ) and metformin showed significant $(\mathrm{P}<0.001)$ reduction in fasting blood glucose levels as compared to diabetic control rats. In addition, the positive control group animals showed significantly lower insulin levels. At the end of $45 \mathrm{~d}$ of treatment, there was a decrease in blood glucose treated with standard (metformin $5 \mathrm{mg} / \mathrm{kg}$, b.w.) and PHF at two different doses (200 and $400 \mathrm{mg} / \mathrm{kg}$, b.w.) showed $42.78 \%, 49.75 \%$ and $41.23 \%$ respectively decrease of glucose level [fig. 2] [table 1].

Effect of PHF on urine volume, serum creatinine, urea and uric acid levels in STZ induced diabetic animals

In the diabetic control group, urine volume was significantly $(\mathrm{P}<0.001)$ increased when compared to the normal control rats. When diabetic rats treated with PHF (Dose-I, $200 \mathrm{mg} / \mathrm{kg}$, Dose-II, $400 \mathrm{mg} / \mathrm{kg})$ and metformin showed significant $(\mathrm{P}<0.001)$ reduction in urine volume as compared to diabetic control rats. Streptozotocin-nicotinamide injection caused a marked reduction in renal function, as characterized by significant $(\mathrm{P}<0.001)$ increase in serum creatinine, urea, and uric acid levels as compared to normal control rats. Thus, these data suggest that a single i. p. injection of STZ-nicotinamide impairs kidney functions. Treatment with PHF 
(Dose-I, $200 \mathrm{mg} / \mathrm{kg}$, Dose-II, $400 \mathrm{mg} / \mathrm{kg}$ ) and metformin showed a significant $(\mathrm{P}<0.001)$ reduction in serum creatinine, uric acid and urea levels as compared to diabetic control rats [table 2].

Effect of PHF on TC, TG, HDL, VLDL and LDL levels in STZ induced diabetic animals

Diabetic control rats showed a significant $(\mathrm{P}<0.001)$ increase in the levels of triglycerides, cholesterol, VLDL, LDL and a decrease in HDL when compared with normal control group. The treatment of diabetic rats with PHF (Dose-I, $200 \mathrm{mg} / \mathrm{kg}$, Dose-II, $400 \mathrm{mg} / \mathrm{kg}$ ) and metformin showed $(\mathrm{P}<0.001)$ decrease in the levels of triglycerides, cholesterol, VLDL, LDL and increase in HDL when compared with diabetic control rats [table 3].

Effect of PHF on SOD, CAT, MDA, GSH levels in Kidney in STZ induced diabetic animals

The content of MDA, the end product of lipid peroxidation and a marker of oxidative stress was significantly $(\mathrm{P}<0.001)$ increased in renal tissue of diabetic control rats as compared to non-diabetic rats. There was a significant $(\mathrm{P}<0.001)$ decrease in the levels of GSH, an endogenous antioxidant and antiperoxidative enzymes (SOD and CAT) in renal tissue as compared to normal control group. The treatment of diabetic rats with PHF (Dose-I, $200 \mathrm{mg} / \mathrm{kg}$, Dose-II, $400 \mathrm{mg} / \mathrm{kg}$ ) and metformin showed a significant $(\mathrm{P}<0.001)$ decrease in the levels of MDA as compared to diabetic control rats and showed a significant $(\mathrm{P}<0.001)$ increase in SOD, CAT and GSH activities [table 4].

Effect of PHF on SOD, CAT, MDA and GSH levels in liver in STZ induced diabetic animals

The results showed that compared with rats in the normal control group, MDA levels in diabetic rats were significantly increased, while SOD, CAT and GSH activity was significantly decreased at the end of the study $(\mathrm{P}<0.001)$. The treatment of diabetic rats with PHF (DoseI, $200 \mathrm{mg} / \mathrm{kg}$, Dose-II, $400 \mathrm{mg} / \mathrm{kg}$ ) and metformin showed a significant $(\mathrm{P}<0.001)$ decrease in the levels of MDA as compared to diabetic control rats and showed a significant $(\mathrm{P}<0.001)$ increase in SOD, CAT and GSH activities [table 4].

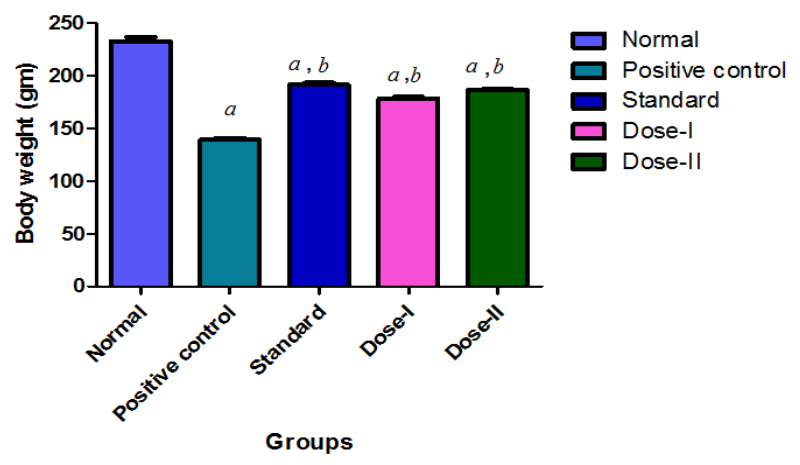

Fig. 1: Effect of PHF and metformin on body weight in STZ induced diabetic animals, values are expressed as mean \pm SEM, $\mathrm{n}=6, \mathrm{a}={ }^{* * *} \mathrm{P}<0.001$ when compared to normal control group, $\mathrm{b}=$ ${ }^{* * *} \mathbf{P}<0.001$ when compared to positive control group

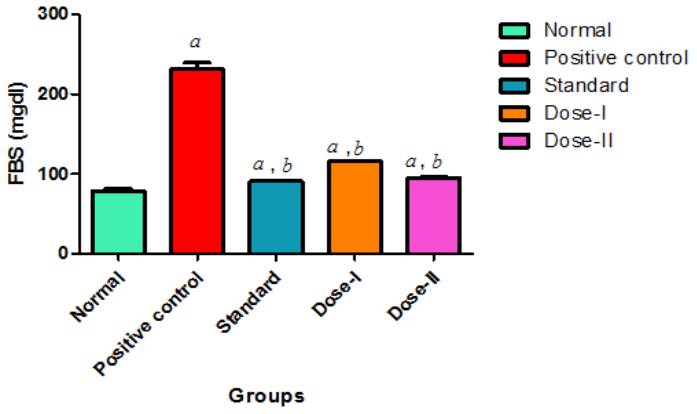

Fig. 2: Effect of PHF and metformin on fasting blood glucose levels in STZ induced diabetic animals, Values are expressed as mean \pm SEM, $n=6, a={ }^{* * *} P<0.001$ when compared to normal control group, $b={ }^{* * *} \mathrm{P}<0.001$ when compared to positive control group

Table 1: Effect of PHF on serum insulin and HbA1c levels in STZ induced diabetic animals

\begin{tabular}{lll}
\hline Groups & Serum insulin ( $\boldsymbol{\mu U} / \mathbf{m l})$ & HbA1c $(\mathbf{m g} \%)$ \\
\hline Normal & $31.06 \pm 0.514$ & $4.275 \pm 0.049$ \\
Positive control (STZ) & $12.02 \pm 0.506^{* * * a}$ & $8.375 \pm 0.096^{* * *} \mathrm{a}$ \\
Standard Treatment (Metformin $5 \mathrm{mg} / \mathrm{kg}$, b.w.)+STZ & $26.72 \pm 0.381^{* * * \mathrm{~b}}$ & $6.105 \pm 0.080^{* * *} \mathrm{~b}$ \\
Dose-I $(200 \mathrm{mg} / \mathrm{kg}$, b.w.)+STZ & $21.22 \pm 0.125^{* * * \mathrm{~b}}$ & $7.325 \pm 0.056^{* * *} \mathrm{~b}$ \\
Dose-II (400 mg/kg, b.w.)+STZ & $25.17 \pm 0.319^{* * * \mathrm{~b}}$ & $6.613 \pm 0.064^{* * * \mathrm{~b}}$ \\
\hline
\end{tabular}

Where, HbA1c-Glycosylate haemoglobin, values are expressed as mean \pm SEM, $n=6 .{ }^{* * *} \mathrm{P}<0.001$, when compared to normal control group (a) and ${ }^{* * *} \mathrm{P}<0.001$, when compared to positive control group (b).

Table 2: Effect of PHF on serum creatinine, urea and uric acid levels in STZ induced diabetic animals

\begin{tabular}{|c|c|c|c|}
\hline Groups & Serum creatinine (mg/dl) & Serum urea (mg/dl) & Serum uric acid (mg/dl) \\
\hline Normal & $0.465 \pm 0.921$ & $23.11 \pm 0.539$ & $1.715 \pm 0.015$ \\
\hline Positive control (STZ) & $1.917 \pm 0.092^{* * * a}$ & $58.47 \pm 0.521^{* * * a}$ & $4.108 \pm 0.021^{* * * a}$ \\
\hline Standard treatment (Metformin $5 \mathrm{mg} / \mathrm{kg}$, b.w.)+STZ & $0.870 \pm 0.023^{* * * b}$ & $44.72 \pm 0.644^{* * * b}$ & $2.427 \pm 0.022 * * * \mathrm{~b}$ \\
\hline Dose-I (200 mg/kg, b.w.)+STZ & $1.357 \pm 0.046^{* * * b}$ & $47.26 \pm 0.293^{* * * b}$ & $3.277 \pm 0.018^{* * * b}$ \\
\hline Dose-II ( $400 \mathrm{mg} / \mathrm{kg}$, b.w.) $+\mathrm{STZ}$ & $1.247 \pm 0.061^{* * * \mathrm{~b}}$ & $37.56 \pm 0.389 * * * \mathrm{~b}$ & $2.735 \pm 0.012^{* * * \mathrm{~b}}$ \\
\hline
\end{tabular}

Values are expressed as mean \pm SEM, $n=6$. ${ }^{* * *} \mathrm{P}<0.001$, when compared to normal control group (a) and ${ }^{* * *} \mathrm{P}<0.001$, when compared to positive control group (b).

Table 3: Effect of PHF on TC, TG, HDL, VLDL and LDL levels in STZ induced diabetic animals

\begin{tabular}{|c|c|c|c|c|c|}
\hline Groups & TC (mg/dl) & TG(mg/dl) & HDL(mg/dl) & VLDL(mg/dl) & LDL(mg/dl) \\
\hline Normal & $91.66 \pm 1.457$ & $111.90 \pm 2.098$ & $35.79 \pm 0.337$ & $22.37 \pm 0.419$ & $33.68 \pm 1.224$ \\
\hline Positive control (STZ) & $182.20 \pm 1.572^{* * * a}$ & $182.60 \pm 1.629 * * * a$ & $25.78 \pm 0.859 * * * a$ & $36.52 \pm 0.325^{* * * a}$ & $119.90 \pm 1.918^{* * * a}$ \\
\hline $\begin{array}{l}\text { Standard (Metformin } 5 \mathrm{mg} / \mathrm{kg} \text {, } \\
\text { b.w.) +STZ }\end{array}$ & $122.80 \pm 1.771^{* * * \mathrm{~b}}$ & $130.40 \pm 1.185^{* * * b}$ & $33.02 \pm 0.485^{* * * b}$ & $26.07 \pm 0.236^{* * * b}$ & $63.74 \pm 2.066^{* * * b}$ \\
\hline Dose-I (200 mg/kg, b.w.)+STZ & $147.10 \pm 1.389^{* * * \mathrm{~b}}$ & $155.10 \pm 0.853^{* * * \mathrm{~b}}$ & $29.76 \pm 0.400^{* * * \mathrm{~b}}$ & $31.02 \pm 0.170^{* * * \mathrm{~b}}$ & $86.33 \pm 1.404^{* * * \mathrm{~b}}$ \\
\hline Dose-II (400 mg/kg, b.w.)+STZ & $132.40 \pm 0.779 * * * \mathrm{~b}$ & $142.90 \pm 0.923^{* * * b}$ & $31.93 \pm 0.366^{* * * b}$ & $28.57 \pm 0.184^{* * * b}$ & $71.93 \pm 1.014^{* * * \mathrm{~b}}$ \\
\hline
\end{tabular}

Where, TC-total cholesterol, TG-triglyceride, HDL-high density lipoprotein, VLDL-very low-density lipoprotein, LDL-low density lipoprotein, values are expressed as mean $\pm S E M, n=6$. $^{* * *} \mathrm{P}<0.001$, when compared to normal control group (a) and ${ }^{* * *} \mathrm{P}<0.001$, when compared to positive control group (b). 
Table 4: Effect of PHF on SOD, CAT, MDA, GSH levels in kidney and Liver in STZ induced diabetic animals

\begin{tabular}{|c|c|c|c|c|c|}
\hline Groups & Organ & $\begin{array}{l}\text { SOD }(\mathrm{U} / \mathrm{mg} \\
\text { protein) }\end{array}$ & $\begin{array}{l}\text { CAT }(\mathrm{U} / \mathrm{mg} \\
\text { protein) }\end{array}$ & $\begin{array}{l}\text { MDA (nmoles/mg } \\
\text { protein) }\end{array}$ & $\begin{array}{l}\text { GSH (nmoles/mg } \\
\text { protein) }\end{array}$ \\
\hline \multirow[t]{2}{*}{ Normal } & Kidney & $9.73 \pm 0.248$ & $55.15 \pm 0.481$ & $1.13 \pm 0.050$ & $16.97 \pm 0.103$ \\
\hline & Liver & $8.77 \pm 0.167$ & $59.00 \pm 0.107$ & $1.27 \pm 0.113$ & $38.93 \pm 0.173$ \\
\hline \multirow[t]{2}{*}{ Positive control (STZ) } & Kidney & $3.03 \pm 0.075^{* * * a}$ & $25.40 \pm 1.201^{* * * a}$ & $6.17 \pm 0.075^{* * * a}$ & $9.08 \pm 0.190 * * * a$ \\
\hline & Liver & $1.12 \pm 0.052^{* * * a}$ & $26.70 \pm 0.114^{* * * a}$ & $14.25 \pm 0.294^{* * *_{a}}$ & $17.98 \pm 0.234^{* * * a}$ \\
\hline \multirow{2}{*}{$\begin{array}{l}\text { Standard (Metformin } 5 \mathrm{mg} / \mathrm{kg} \text {, } \\
\text { b.w.)+STZ }\end{array}$} & Kidney & $6.21 \pm 0.127^{* * * \mathrm{~b}}$ & $48.58 \pm 0.427^{* * * b}$ & $2.04 \pm 0.051^{* * * \mathrm{~b}}$ & $14.21 \pm 0.196^{* * * b}$ \\
\hline & Liver & $7.66 \pm 0.149^{* * * b}$ & $54.64 \pm 0.218^{* * * b}$ & $2.51 \pm 0.127^{* * * \mathrm{~b}}$ & $37.01 \pm 0.346^{* * * \mathrm{~b}}$ \\
\hline \multirow[t]{2}{*}{ Dose-I (200 mg/kg, b.w.)+STZ } & Kidney & $4.95 \pm 0.048^{* * * \mathrm{~b}}$ & $42.77 \pm 0.431^{* * * b}$ & $2.97 \pm 0.071^{* * * \mathrm{~b}}$ & $12.00 \pm 0.077^{* * * \mathrm{~b}}$ \\
\hline & Liver & $4.54 \pm 0.145^{* * * \mathrm{~b}}$ & $45.98 \pm 0.166^{* * * b}$ & $4.06 \pm 0.093^{* * * \mathrm{~b}}$ & $33.11 \pm 0.179^{* * * b}$ \\
\hline \multirow{2}{*}{ Dose-II (400 mg/kg, b.w.)+STZ } & Kidney & $5.25 \pm 0.039 * * * \mathrm{~b}$ & $46.01 \pm 0.428 * * * b$ & $2.19 \pm 0.034^{* * * \mathrm{~b}}$ & $13.18 \pm 0.115^{* * * b}$ \\
\hline & Liver & $6.91 \pm 0.082^{* * * \mathrm{~b}}$ & $53.07 \pm 0.280 * * * \mathrm{~b}$ & $3.02 \pm 0.058^{* * * \mathrm{~b}}$ & $35.44 \pm 0.160^{* * * \mathrm{~b}}$ \\
\hline
\end{tabular}

Where, SOD-superoxide dismutase, CAT-catalase, MDA-malondialdehyde, GSH-glutathione, values are expressed as mean \pm SEM, $n=6$. ${ }^{* * *} \mathrm{P}<0.001$, when compared to normal control group (a) and ${ }^{* * *} \mathrm{P}<0.001$, when compared to positive control group (b).

\section{Histopathological studies of kidney, liver and pancreas}

The tubules of the kidney showed some degenerative changes and few blood vessels were congested with diabetic control rats as compared to normal structural features of a control animal. In the normal control group, the histopathological examination of kidney tissue showed the normal appearance of glomeruli and tubules (long arrow). Treatment with Dose-I $200 \mathrm{mg} / \mathrm{kg}$ (PHF) showed some degenerative changes. However, treatment with Dose-II $400 \mathrm{mg} / \mathrm{kg}$ and metformin showed intact architecture as compared to normal group [fig. 3]

Section studied in positive control rats shows the liver parenchyma having partially distorted architecture and there are seen focal areas of necrosis (short arrow) with congested blood vessels as compared to normal control group $\{$ [shows intact architecture] (long arrow)\}.
Treatment with PHF (Dose-II, $400 \mathrm{mg} / \mathrm{kg}$ ) shows the liver parenchyma having intact architecture and the perivenular, periportal and midzonal hepatocytes appear unremarkable. The central veins and sinusoids appear unremarkable as compared to positive control group [fig. 4].

Section studied shows in positive control rat that pancreatic lobules separated by connective tissue septa. The centre of islet cells consists of a quantitative decrease in small $\beta$-cells (long arrow) $(30 \%$, compared to normal control, $70 \%)$, while the periphery comprises of large $\alpha$-cells (short arrow) (65\%, compared to normal control, 25\%). Treatment with PHF (Dose-II, $400 \mathrm{mg} / \mathrm{kg}$ ) shows regeneration of $\beta$-cells $(70 \%$, compared to positive control group $30 \%)$, while the periphery comprises of large $\alpha$-cells $(25 \%$, compared to positive control group 65\%) [fig. 5].
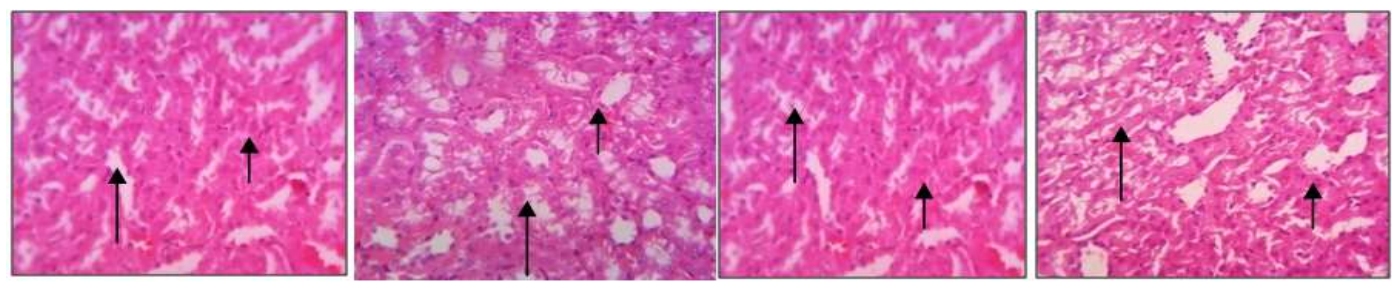

Fig. 3: Histopathology of kidney tissues from rats. (a) Normal control group, (b) Positive control group, (c) Standard (d) Dose-II 400 $\mathrm{mg} / \mathrm{kg}$ (H and $\mathrm{E} 400 \times$ ), Where, $\mathrm{H}$ and E-Hematoxylin and eosin
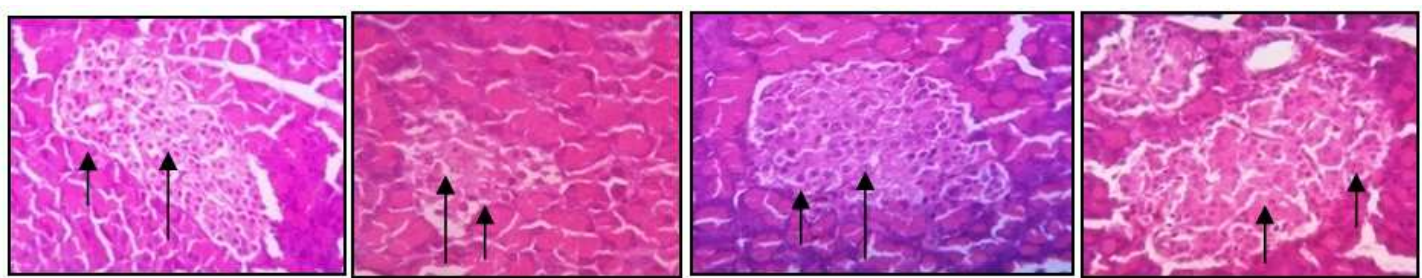

Fig. 4: Histopathology of pancreas from rats. (a) Normal control group, (b) Positive control group, (c) Standard (d) Dose-II $400 \mathrm{mg} / \mathrm{kg}$ (HandE 400x), Where, $\mathrm{H}$ and E-Hematoxylin and eosin
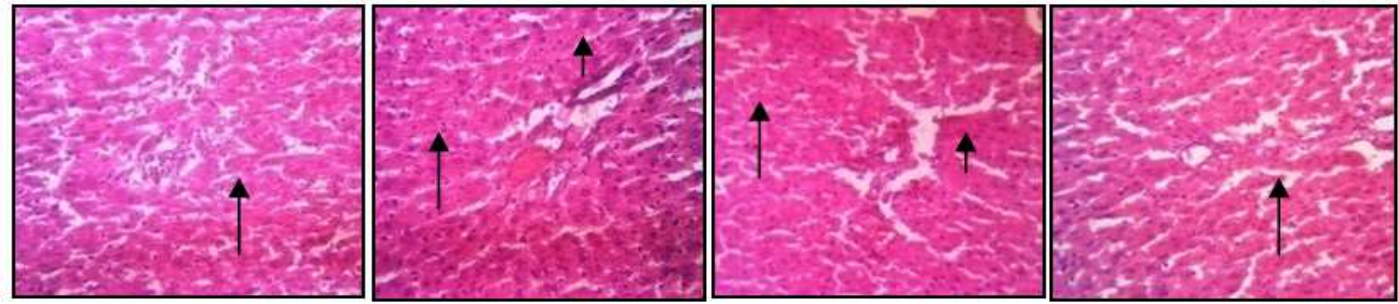

Fig. 5: Histopathology of liver from rats. (a) Normal control group, (b) Positive control group, (c) Standard (d) Dose-II $400 \mathrm{mg} / \mathrm{kg}$ (H and E 400x), Where, $H$ and E-Hematoxylin and eosin 


\section{DISCUSSION}

DM is a long-term disorder characterized by elevated blood glucose level due to absolute or relative insulin deficiency [18]. The present study was undertaken to evaluate antidiabetic, hypolipidemic and antioxidant activities of PHF in normal rats, STZ-induced untreated rats and treated diabetes rats with PHF and metformin.

STZ-induced hyperglycemia is a widely applied experimental model because of the ability of STZ to selectively target and destroy insulinproducing pancreatic islet $\beta$-cells. The intraperitoneal administration of STZ $(65 \mathrm{mg} / \mathrm{kg})$ partially damages the insulinsecreting pancreatic $\beta$-cells by breaking the DNA strand, which results in increased blood glucose levels and decreased in endogenous insulin release. Oral administration of PHF (200 and $400 \mathrm{mg} / \mathrm{kg}$ ) resulted in significant reduction in fasting blood glucose levels. The increased serum insulin levels in PHF treated STZdiabetic rats could be due to the protection of function $\beta$-cells from further deterioration. Increased levels of insulin might help in improving glycemic control in STZ-diabetic rats.

In our study, the body weight of STZ-induced untreated diabetic group showed a significant decrease. Oral administration of PHF at a dose of $400 \mathrm{mg} / \mathrm{kg}$ for $45 \mathrm{~d}$ showed an improvement in body weight in comparison to diabetic control and rats treated with metformin. The higher body weight of PHF treated rats might be due to their improved glycemic control.

HbA1C levels are monitors as a consistent index of glycemic control in diabetes [19]. Administration of PHF results in decreased fasting blood glucose levels, further leading to significant reduction in HbA1C levels in diabetic rats.

The most commonly observed lipid abnormalities in diabetes are hypertriglyceridemia and hypercholesterolemia [20]. The excess of fatty acids in the plasma may support the hepatic conversion of fatty acids into phospholipids and cholesterol. These changes may usually lead to secondary complications of diabetes such as atherosclerosis and increased coronary heart disease. Our results indicate lipid profiles viz cholesterol, triglyceride, VLDL and LDL were reduced significantly by PHF administration. HDL plays a key role in protecting against heart disease because of its role in the transportation of excess cholesterol out of the body and is known as "good cholesterol". In the present study, PHF significantly increased the HDL level in treated diabetic animals.

Oxidative stress plays a crucial role in the development of hyperglycaemia, which generates reactive oxygen species (ROS) causing cellular injury and several deleterious effects on cellular physiology and these have a key role in the development of secondary complications of diabetes. An elevated level of MDA in diabetic put forward for consideration that peroxide injury may be involved in diabetic complications. In the present study, a marked increase in the levels of tissue malondialdehyde (MDA) content in STZ-diabetic rats leading to tissue injury and failure of antioxidant defence mechanism. The diabetic rats treated with PHF significantly decreased the levels of MDA in kidney and liver [21]. Several studies indicated that there is a generation of oxygen free radicals in STZ-treated $\beta$-cells and that the overexpression of antioxidant enzymes, such as SOD, CAT. Reduced activities of SOD and Cat in liver and kidney have been observed during diabetes. SOD is vital defence enzyme which catalyses the dismutation of superoxide radicals. CAT is a heme protein which catalyses the reduction of hydrogen peroxide and protects the tissues from highly reactive hydroxyl radicals [22]. Low activity of catalase which has been reported with schizophrenia and atherosclerosis [23] are the same way with the assumption that long-term oxidative stress may lead to development to type 2 diabetes. Our results indicate that treatment with PHF significantly increased the SOD and CAT levels in kidney and liver. PHF treated diabetic rats also significantly increase the levels of GSH in vital organs of rats.

Histopathology studies of the pancreas showed that degeneration of $\beta$ cells of the islets with a reduction in mass of islet cells in positive control rat. Groups treated with PHF showed regeneration of $\beta$-cells and increase in mass of islets as compared to positive control rats. Metformin $(5 \mathrm{mg} / \mathrm{kg})$ treated diabetic rats also showed regeneration of $\beta$-cells. Histopathology of kidney revealed that PHF significantly enhanced the normal appearance of glomeruli and tubules and also showed intact architecture when compare to positive control rats which showed degenerative changes and few blood vessels congestion.

Histopathology studies of liver also revealed the protective effect of PHF. Treatment with PHF showed the intact architecture of liver parenchyma and the perivenular, periportal and midzonal hepatocytes. The central veins and sinusoids appear unremarkably normal compared to the positive control group which showed the liver parenchyma partially distorted.

\section{CONCLUSION}

In conclusion, data from the present study states that the PHF has potent antidiabetic, hypolipidemic and antioxidant activities. Biochemical and histopathological results of study also revealed the degree of protection offered by PHF to diabetic animals. Further studies are required for bioactivity guided drug discovery to isolate lead compounds, which may be responsible for these claimed activities.

\section{ACKNOWLEDGEMENT}

The authors are thankful to Green Chem Herbal Extracts and Formulations, Domlur, Bangalore.

\section{AUTHOR CONTRIBUTION}

Dr. Purnima Ashok-The present work was initiated by the author.

Yuvraj Singh Surana-Author has contributed the major experiment part.

Rajendran R.-Author has helped in the statistical analysis.

\section{CONFLICT OF INTERESTS}

The authors state that they have no conflicts of interest.

\section{REFERENCES}

1. Dnyaneshwar MN, Pankaj SK, Vipin DB, Nitin BG, Archana RJ. Antidiabetic and antihyperlipidemic activity of Pithecellobium dulce (Roxb.) Benth seeds extract in streptozotocin-induced rats. Eur J Integra Med 2015;7:263-73.

2. Navpreet K, Lalit K, Randhir S. Antidiabetic effect of new chromane isolated from Dillenia indica L. leaves in streptozotocin-induced diabetes rats. J Func Foods 2016;22:547-55.

3. Chin-Shiu H, Mei-Chin Y, Lan-Chi C. Antihyperglycemic and antioxidative potential of Psidium guajava fruit in streptozotocin-induced diabetic rats. Food Chem Toxicol 2011;49:2189-95.

4. Cadd WT. Diabetes-related microvascular and macrovascular diseases in the physical therapy setting. J Am Physical Ther Association 2008;88:1322-35.

5. Mamdouh MA, Abdel-Raheim MAM. Oxidative stress in streptozotocin-induced diabetic rats: effects of garlic oil and melatonin. Comp Biochem Physiol Part A 2003;135:539-47.

6. Subramaniam R, Aiyalu R, Manisenthi KTK. Antidiabetic, antihyperlipidemic and antioxidant potential of methanol extract of Tectona grandis flowers in streptozotocin-induced diabetic rats. Asian Pac J Trop Med 2011;4:624-31.

7. Bhatt $M$, Gahlot $M$, Juyal V, Singh A. Phytochemical investigation anti-diabetic activity of Adhatoda zeylanica. Asian J Pharm Clin Res 2011;4:27-30.

8. Rajesh R, Chitra K, Padmaa MP. Antihyperglycemic and antihyperlipidemic activity of aerial parts of Aerva lanata Linn Juss in streptozotocin-induced diabetic rats. Asian J Trop Biomed 2012;2:924-9.

9. Lawrence L, Richard B, Jyoti K, Susan H, Sharon C. Anti-diabetic and hypoglycaemic effects of Momordica charantia (bitter melon): a mini review. Br J Nutr 2009;102:1703-8.

10. Chhanda M, Kausik C, Mehuli GB, Debidas G. Antihyperglycemic effects of separate and composite extract of root of Musa paradisiaca and leaf of Coccinia indica in streptozotocin-induced diabetic male albino rats. Afr J Trad CAM 2007;4:362-71.

11. Guy K, Jaekyung K, Klaus H, Yanyan C, Xiaozhuo C. Antidiabetes and anti-obesity activity of Lagerstroemia speciosa. eCAM 2007;4:401-7. 
12. Anu $\mathrm{C}$, Abbas $\mathrm{AM}$, Sohil $\mathrm{A}$, Raj KS. Indian herbs result in hypoglycaemic responses in streptozotocin-induced diabetic rats. Nutr Res 2007;27:161-8.

13. Guidance document on acute oral toxicity testing, series on testing and assessment No. 24, an organization for economic co-operation and development, OECD Environment, health and safety publications, Paris; 2001.

14. Pompella A, Visvikis A, Paolicchi A, De Tata V, Casini AF. The changing faces of gluthione, a cellular pathogonist. Biochem Pharmacol 2003;66:1499-503.

15. Sinha AK. Colorimetric assay of catalase. Anal Biochem 1972;47:389-94.

16. Kakkar P, Das B, Viswanathan PN. A modified spectrophotometric assay of superoxide dismutase. Indian J Biochem Biophys 1984;21:130-2.

17. Ohkawa H, Ohisi N, Yagi K. Assay for lipid peroxides in animal tissues by thiobarbituric acid reaction. Anal Biochem 1979;95:351-8.

18. Malini P, Kanchana G, Rajadurai M. Antidiabetic efficacy of ellagic acid in streptozotocin-induced diabetes in albino wistar rats. Asian J Pharm Clin Res 2011;4:124-8.
19. Babu PS, Prabuseenivasan S, Ignacimuthu S. Cinnamaldehyde-A potential antidiabetic agent. Phytomedicine 2007;14:15-22.

20. Ravi K, Rajasekaran S, Subramanian S. Antihyperlipidemic effect of Eugenia jambolana seed kernel on streptozotocininduced diabetes in rats. Food Chem Toxicol 2005;43:1433-9.

21. Tiwari BK, Pandey KB, Pandey KB, Abidi AB, Rizvi SI. Markers of oxidative stress during diabetes mellitus. J Biomark 2013:18. http://dx.doi.org/10.1155/2013/378790

22. Vuppalapati L, Velayudam R, Ahamed KFHN, Cherukuri S, Kesavan R. The protective effect of dietary flavonoid fraction from Acanthophora spicifera on streptozotocin induced oxidative stress in diabetic rats. Food Sci Hum Well 2016;5:57-64.

23. Goth L, Vitai M. Hypocatalasemia in hospital patients. Clin Chem 1996;42:341-2.

\section{How to cite this article}

- Yuvraj Singh Surana. Evaluation of antidiabetic, hypolipidemic and antioxidant activity of polyherbal formulation in streptozotocin-nicotinamide induced diabetes in rats. Int J Pharm Pharm Sci 2017;9(10):105-110. 